\title{
A Fresh Apple or a New Barrel: Business Ethics from an Individual to Corporate Level
}

\author{
Sibel Oktar Thomas \\ Ozyegin University, Istanbul Turkey
}

\begin{abstract}
The moral nature of corporations has been discussed for a long time. But, since 2001, with enormous economic effects of the misconduct of some corporations this discussion gained another dimension, it moved into the public sphere, the subject became more sensitive. The anger and mistrust of the public toward business triggered legislators and corporations to take urgent action. For example, just after the collapse of Enron (2001) the American Congress passed the Sarbanes-Oxley Act (2002) that covers the responsibilities of boards of directors and requires compliance training at all levels. It also revived the old controversial arguments about the nature of business - whether the only purpose of business is to make profits, the relationship of business and ethics - whether business ethics is an oxymoron, and human nature - whether it is 'bad apples' or 'bad barrels'. Yet, with new sets of regulations, in 2017, we are still witnessing the misconduct of corporations on a global scale. This article investigates the effectiveness of corporate efforts such as revisiting mission statements, polishing the codes of ethics and conducting training, by evaluating the nature of business, human nature and the understanding of ethics in the workplace. By looking through the lens of utilitarianism of ethical issues in business, I will argue that codes of ethics and ethics training are necessary but not sufficient. Within the scope of this paper I wish to pave the way to a holistic approach which is necessary and sufficient to create ethical businesses.
\end{abstract}

Keywords: Business ethics, code of ethics, training, bad apples, utilitarianism

\section{Introduction}

\section{A Fresh Apple or a New Barrel: Business Ethics from an Individual to Corporate Level}

It is not surprising that the moral nature of corporations has been discussed for a long time since activities of business affect us in most of our dealings. Our role as a stakeholder varies - shareholder, manager, employee, supplier, customer, member of a local community, etc. - but we remain affected by the decisions taken by business. Economists, social scientists, especially management scholars along with philosophers started to show an interest in Business Ethics as a subject matter since the mid-1970s, and by the late 1980s and early 1990s descriptive ethical theories in this area started to emerge (O'Fallon \& Butterfield, 2005). With the bankruptcies of Enron and WorldCom many stakeholders suffered and since 2001 the misconduct of some corporations has taken this discussion to another dimension, it moved into the public sphere, the subject became more sensitive. The anger and mistrust of the public toward business triggered legislators and corporations to take urgent action. For example, just after the collapse of Enron (2001) the American Congress passed the Sarbanes-Oxley Act (2002) that covers the responsibilities of boards of directors and requires compliance training at all levels. Even with new sets of regulations the global economic crisis in 2008 caused mainly by the misconduct of corporations, and yet in 2017 we are still witnessing the misconduct of corporations on a global scale. 
This continuity of misconduct and unethical behaviour revived the old controversial arguments about the nature of business - whether the only purpose of business is to make profits, the relationship of business and ethics - whether business ethics is an oxymoron, and human nature - whether it is 'bad apples' or 'bad barrels'

In order to have a framework for our understanding of human nature I would like to briefly clarify these aforementioned arguments about the nature of business and its relationship with ethics. First of all, why has it been claimed that business ethics is an oxymoron? Obviously, if we accept this claim there is no need for further discussion. It is worth investigating the underlying assumption of this proposition, since; it indicates the cynicism of individuals towards business and becomes a discussion topic again and again in every business scandal.

John W. Collins (1994) states that the idea that business ethics is an oxymoron arises from the traditional view of the managerial role which is, as Milton Friedman (1970) puts it an executive's primary responsibility is to his employer. He states that:

"In a free-enterprise, private-property system, a corporate executive is an employee of the owners of the business. He has direct responsibility to his employers. That responsibility is to conduct the business in accordance with their desires, which generally will be to make as much money as possible while conforming to basic rules of the society, both those embodied in law and those in ethical custom."

Friedman makes the distinction between an executive as an agent and an executive as a principal (Fryer, 2015), as a principal she can engage any kind of activity she wishes and can use her own money and time. But, as an agent she cannot use her employer's money or time because she willingly contracted her time and energy to devote to the purposes of her employer. To say that an executive has a social responsibility as a business person "mean that he is to act in some way that is not in the interest of his employers" (Friedman, 1970). Is Friedman's view invalid in 2017? It has been criticized widely but, also supported by many, including Peter Drucker and Noam Chomsky (Bakan, 2004). How could this be?

Due to the purpose of business - to maximize profit. - Its self-interest and self-concern clashes with any ethical concern for others (Collins, 1994). Collins (1994) states that participants in business activities need to cooperate since these activities are interdependent on each participant's success and these situations require a non-zero-sum game which includes winwin situations. Although with a different understanding Friedman is not opposed to such a win-win situation. In his interview with Joel Bakan (2004) he stated that if an executive treats social and environmental values as a means to end, corporate social responsibility is permissible. Bakan states that "Friedman acknowledges that this purely strategic view of social responsibility reduces lofty ideals to "hypocritical window dressing." But hypocrisy is virtuous when it serves the bottom line."(Bakan, 2004, p.35)

If we accept that the only aim of business is to make profit and human beings are self-interested and any attempt of business for social responsibility is a means to an end then should we conclude that there is no such thing as ethics in business? Not necessarily. Surely, if we take into account the ethics of Immanuel Kant, although they are doing the right thing, corporations 'window dressing 'activities are amoral, they are not the subject matter of ethics. But, according to consequentialist approaches, rather than the intention of the doer, the consequences of the act determine whether it is ethical or not. Thus, window dressing or not if the consequences of the action is good, it is in the realm of ethics. One must not drive the conclusion that Kantian Ethics or other deontological approaches have no place in business ethics studies; instead what is indicated is that there are different ethical theories that could provide us different frameworks. The framework of this paper is preferably utilitarian in nature and claims that being self-interested or having a goal of maximizing profit is compatible with ethics, but not that human nature is mainly self-interested.

Empirical studies on 'links between ethical theories and management decision making' mainly rely on the distinction between deontological and teleological theories. Although, research results show a general tendency of managers to use a utilitarian framework in decision making (O'Fallon \& Butterfield, 2005; Craft, 2013) Premeaux (2004) states that although 
their findings show similarities to that of 1990s that managers still have a high tendency to rely on utilitarian theory, "more managers are now likely to select ethically appropriate actions either because it is ethical to do so, or because the consequences or risk of not doing so are too great." (Premeaux, 2004, p.269) This is consistent with earlier studies, when people were asked why they made certain decisions things are getting more complicated. Rather than simply choosing between this is not an acceptable behaviour and this is an acceptable behaviour explaining why it is acceptable or not involves more variables that is hard to control. Fritzche and Becker (1984), in their study asked managers to respond several vignettes on a 0 to 10 point Likert scale and later asked them why they made a particular decision and classify the responses by type of ethical theory. They considered utilitarian theories, theories of right and theories of justice and also they searched the difference between act and rule utilitarianism. Their findings will be discussed later, but here it is worth mentioning their comment, which is "Individual responses tended to be well thought out and somewhat complex" (Fritzche and Becker, 1984, p.169) This is somewhat consistent with Brady \& Wheeler's (1996) findings that in regard to ethical predispositions, rather than the reasons that support the solutions people are "strongly biased toward solutions" and thus they drove the conclusion that their study "implies that utilitarianism and formalism are not best understood as forms of reasoning but as general behavior-orientations that can be independently rationalized"(Brady \& Wheeler, 1996, p.937).

In the Groundwork of the Metaphysics of Morals Kant wants us to consider the case of a shopkeeper and a merchant who both act honestly and who do not overcharge their customers even if the customer is a child or an inexperienced person. The shopkeeper acts honestly because he thinks that it is the right thing to do while the merchant acts honestly because he foresees a good deal of trade in the future. For Kant, the merchant cannot be said to have acted out of duty, but only "for purposes of self-interest" (AK: 4:397, p.11). Although the consequences of the merchant's act may be good, he behaves so because it is good for future trade and for his own interest, and not because it is the right thing to do for its own sake. Thus, the merchant's behaviour has nothing to do with ethics or value. Imagine that we have a chance to ask the merchant and the shopkeeper to rate the acceptability of overcharging inexperienced customers, as neither has overcharged inexperienced customers they will both rate it as unacceptable. Then if we ask them to state the reason why they think it is unacceptable what will they say. The shopkeeper would say that to act honestly is the right thing to do. Would it be that easy for the merchant to say that to act honestly is good for future business that is why the act in question is not acceptable? Such an argument can be interpreted that if he thinks that in some cases if he sees an opportunity in business by acting dishonestly then he could go for it. Would not it be easier for him to rationalize his decision on the basis that acting honestly is the right thing to do? Social desirability bias needs to be considered.

Analysing the consequences of an act rather than the intention of it seems more practical and close to the decision making strategies of managers that are used for daily business decisions not related to ethical issues. For example, Cohen and Sharp's (1993) research findings show that in ethical decision making of accounting academics that elements of a utilitarian framework are evident. As cost-benefit analysis is fundamental to accounting based decision making, they suggest that " in other business disciplines the use of a cost/benefit principle may also be embedded in the subject area that it lends itself to the use of a utilitarian construct" (Cohen and Sharp, 1993, p. 22).

If we are going to apply a utilitarian approach then it is inescapable to mention the importance of reward and punishment. This does not imply that the utilitarian approach is based on reward or punishment, but these outcomes are the things that we want to gain or avoid and inevitable ingredients or part of a whole that leads us to the desirable end. Performance management systems are the main tools that corporations use to direct employees to work in line with their goals. Through reward and/or punishment, corporations try to enhance an expected performance. It is believed that performance management is a key ingredient to establish the ethical culture of organizations, whether it is moral, amoral or immoral. Although considering reward or punishment as a basis of moral conduct seems undesirable it reflects the common understanding of morality. More than 2500 years ago, in Plato's Republic, Socrates and Glaucon discusses why one should be moral and Glaucon tells the story of the Ring of Gyges, where a shepherd called Gyges finds a ring that gives him the power of invisibility, which gives him a chance to get away with anything. And he concludes that if it was not for the fear of 
punishment "the "just" and the "unjust" person would both behave in the same way: unjustly, immorally." (Plato, 1974, Book $2,359 \mathrm{~d}-360 \mathrm{c}$ ) Socrates challenges this view and provides Plato's account of why one should be moral. Here, the point is, although it is a very controversial topic, Glaucon's account of morality in terms of punishment and reward is still valid. And this understanding of morality brings us back to the discussion of the self-interested nature of human beings.

Although the doctrine of self-interest has negative connotations (Cropanzano ,Stein \& Goldman, 2007)it is widely used to understand and explain human behaviour, it has been criticized that the self-interest assumption becomes a norm that determines how people act (Miller, 1999) and how our assumptions become self-fulfilling including the most fundamental idea of economics, i.e., idea of self-interest (Ferraro, Pfeffer, Sutton, 2005). There is extensive research on self-interest. Cropanzano, Stein, and Goldman (2007, p.212) searched for the answer of whether there was anything beyond selfinterest, by covering philosophical, economic, social psychological, management science, political science and biological perspectives exploring ancient to contemporary thought and their conclusion was "Each time we turned over a stone, we found evidence for self-interest. To be sure, humans are egoistic creatures. However people are not only egoistic. No single motive, even self-interest, is sufficient account for all our behaviour."

This way of understanding of human nature also finds its place in discussion of business ethics in different forms. The idiom 'one bad apple spoils the barrel' is used to state that self-interested people with no ethical concerns could corrupt the institutions. Volkswagen's(VW) U.S. chief executive at House subcommittee hearing on the claim that the company was violating public trust by cheating on emission tests said that: "This was a couple of software engineers who put this in for whatever reason. ... To my understanding, this was not a corporate decision. This was something individuals did." (Eisenstein, 2015) Thus a few bad apples caused such a scandal which spoiled the company. People- including the House committee- were quite sceptical of Volkswagen's claim of bad apples. Briefly, the 'bad apples' argument attributes unethical behaviour in the organizations to a few individuals, as it happened in the case of VW. Whereas the 'bad barrels' argument attributes the unethical behaviour to the organizational environment. Here, something in the barrel poisons good apples (Trevin o \& Youngblood, 1990). This distinction between society and individuals as the cause of moral behaviour goes back to Thomas Hobbes and Jean-Jacques Rousseau's definition of the nature of human beings and the nature of society, Hobbes and Rousseau have two different views, it can be said that Hobbes would support the 'bad apple 'argument whereas Rousseau would support the 'bad barrel' argument. Rousseau,(2015, p.7) states that "Our will is always for our own good, but we do not always see what that is; the people is never corrupted, but it is often deceived, and on such occasions only does it seem to will what is bad." Mick Fryer discusses the philosophical bearings in combination of business cases extensively and how different ethics management systems work for each approach (Fryer, 2015, pp. 139-155).

If we think that the cause of unethical behaviour in organizations is a few bad apples then to deal with unethical behaviour seems easier to deal with a few individuals then dealing with the organizational environment. Codes of ethics, performance management systems and recruiting policies would help organizations to identify these bad apples and take them out of the barrel before they spoil the rest of the apples. As mentioned before, legislator's efforts to establish certain principles to prevent corruption in organizations and the organizations' emphasis on their codes of ethics, value statements, health and safety even to establish ethics training did not stop corporate scandals. We do not need to go back to the explosion of Ford Pinto's; we have the Samsung Galaxy Note 7 catching fire in 2016. It may appear that expediency overcome ethics. Surely Samsung has a code of ethics. Samsung's website (http://www.samsungcnt.com/eng/governance/codeofEthics.do) gives comprehensive information on their code of ethics and even provides four questions to ask, "whether the behaviour is against the law, against Samsung code of ethics, against conscience and whether a behaviour benefit or harm any person unfairly" while they are making their own judgement of behaviour. Volkswagen not only has code of ethics but also a detailed Whistle-blower System (https://www.volkswagenag.com/). Yet, both Volkswagen and Samsung could not prevent a few bad apples spoiling the barrel.

Recent research results seem to be controversial on the effect of codes of ethics on the ethical decision making process, some of the studies indicate that the existence of a codes of ethics is not sufficient to influence ethical behaviour (Craft, 2013). This is consistent with the above mentioned examples. It is not to say that a code of ethics is obsolete, rather that there is something wrong with the implementation of it. The mere existence of any policy does not necessitate the use of it unless not using it has an effect on people. Human Resources practitioners know very well that when they introduce a policy without the support of the majority of the management team this policy is doomed to fail. The effectiveness of codes 
of ethics is not up to the 'bad apples' but mainly the 'bad barrel'. Thus, how the code of ethics operates and is integrated into the other management decision systems of the company needs to be investigated to understand its effectiveness. Empirical research findings provide evidence to the view that when organizations encourage an ethical culture, discipline unethical behaviour and act upon wrongdoings when it is reported "observers will have more confidence that their reporting will be considered as legitimate and appropriate, and accepted by management and co-workers" (Zhang et al., 2009, p.30).

Kish-Gephart, Harrison, and Trevino's (2010, p.12) research shows that even though their hypothesis on organizational environment characteristics, that "strength of an egoistic climate would increase the likelihood of unethical choices" was supported by results, the "effect is somewhat weak" It seems like there are indicators but not conclusive evidence. Whereas their hypothesis that "a stronger ethical culture would be inversely related to fewer unethical choices" was affirmed by the results "with a robust, negative correlation $\left.{ }_{-}{ }_{-} .329, \mathrm{k}_{-} 12, \mathrm{n}_{-} 2,969\right)$." I will not disagree with the comment that bad apples contribute to unethical environment, which is inevitable, that the concern is to consider it as the sole component of the unethical behaviour of organizations. Obviously, Kish-Gephart, Harrison, and Trevino (2010, p.17) are aware of it and suggest that researchers need to study "bad apples, cases, and barrels simultaneously." Research on moral decision making also suggests that in order to improve the ethical environment organizations need to establish a code of ethics, (O'Fallon .and Butterfield, 2005, Craft, 2013) which is a sound suggestion, but Deshpande's (2009, p. 393) suggestion is even more powerful which is "in addition to a code of ethics, it is important to have a process in place that ensures that ethical considerations are a part of the decision-making process used by employees."

Thus, practice and research suggest organizations need to integrate the code of ethics and their value statements, if any, to other organizational decision making processes. The most obvious candidate being performance management systems. When one mentions performance management the first thing that comes to mind is performance appraisal, it is an important tool, but it is only one component of the system. Performance management as a system has several components and many seemingly separate activities like training and disciplinary actions covered within this system. What organizations reward or punish their employees for is just as important as how they do it. It is customary and just to reward high performance, but how an organization defines and measures high performance makes a difference. If a salesperson has an outstanding sales record, but deceives the customer, would it be acceptable? Kish-Gephart, Harrison, and Trevino (2010, p. 2) make the interesting point that "it is possible for a behaviour to violate widely accepted societal norms while remaining normative in the organization (e.g., lying to customers)" It is hoped that lying to customers exists as an informal norm, but not as an organizational norm. It cannot be accepted that violations of societal norms be regarded as normative within an organization. Otherwise, the other salespeople who would not lie the customers "would be thought by the lookers-on to be a most wretched idiot" (Plato, 359d-360c) as Glaucon would suggest in the story of the Ring of Gyges. Having informal norms that encourage unethical behaviour should not be acceptable. If the performance management systems of the organizations fail to define and eliminate these informal norms there is no chance of a positive effect of a code of ethics.

Empirical studies indicate that employees with high performance, creative talent or high job status are regarded as high valued employees and managers are either reluctant to discipline them or perceive their otherwise offensive behaviour less serious and significantly less unethical (Rosen and Jerdee, 1974). Unfortunately, practice also confirms these findings. That is the time to question the barrel and sterilize it. If an organization is sincere about its value statements and code of ethics, it must be embedded into all its practices and it must be applied to everyone without exception.

Why should business be reluctant to sincerely act ethically? Is it because most of the time acting ethically contradicts the idea of maximizing profit? Should it be so? If we do not expect business to engage in activities just because it is the right thing to do or because it is their duty to do so, if we do not consider doing the right thing as a means to an end as hypocrisy - it is not meant to pretend to do the right thing but doing the right thing with different incentives - and if we do not deny the self-interested nature of human beings, if our expectations of corporate social responsibility (CSR) do not go to the top of the well-known CSR pyramid, i.e., philanthropic responsibilities but as Friedman suggests "conforming to basic rules of the society, both those embodied in law and those in ethical custom', is it possible to make acting ethically and making profit compatible? 
It seems that in order to achieve compatibility we are giving away a lot, indeed we are not, we are not trying to alter their purpose, i.e., profit, acting ethically will serve this purpose and business, rather than trying to rationalize the acts to be seen ethical, they could start to act ethically. We are offering a 'fresh barrel.' We are asking business to use a utilitarian framework when it is making business decisions. As aforementioned research results shows when we see the way managers make decisions, we must mention that there is no such thing as a purely business decision that has nothing to do with ethics, almost all business decisions have ethical implications. How to invest, where to invest, which financial tools to use, where to build your factory, which suppliers to use and many other decisions which seem like pure business decisions, all have ethical implications. If the supplier you choose to work with, abuses its employees or uses 'sweat shops' or child labour we are confident that it is an ethical decision. While a company is deciding to work with which supplier, it makes a cost-benefit analysis, if not it is not pursuing its own purpose, to make profit. If they use a utilitarian framework, they should continue to do the cost-benefit analysis as they are accustomed to and analyse the consequences of working with this particular supplier, in line with stakeholder theory, the utilitarian approach demands that they consider all the relevant parties. The principle of utility states that morally right action is the one that, among all alternative actions, that produces as much good for all people affected by this action (Lawhead, p. 473). Moreover each party's happiness counts equally. You might ask why should business care about the good produced for all parties? Why should a company care how the supplier treats its own employees as long as it provides products with low cost? Well, because it serves its self-interest.

Before mentioning the impact of the stakeholders, through the public sphere, to the bottom line of the companies in this era of communication, it is worth mentioning two lab experiments that will help us understand how this self-interest works also for the benefit of others. Fieke Hanrick and colleagues (2000) designed an experiment (as cited in Greene, 2013) where pairs of strangers negotiate on four hypothetical criminal cases where they randomly assigned the role of defence lawyer or district attorney, according to roles each of the participants received confidential documents outlining the good and bad outcomes from their point of view. Outcome values of two cases were arranged as a "zero sum" game and outcome of the two other cases as "win-win" solutions. Some pairs were told to think about the negotiation in self-interest terms and others in moral terms. As mentioned before, in order to achieve cooperation in business activities for the success of each participant, suggests that a non-zero-sum game which includes win-win situations is required (Collins 1994). However, the results show that the pairs told to negotiate considering self-interest did better in arriving at win-win solutions than the pairs that seek justice (Greene, 2013, p.87). Joshua Greene (2013, p.88) concluded that "two selfish and rational negotiators who see that their positions are symmetrical will be willing to make the concessions necessary to enlarge the pie, and then split the pie evenly." Thus, being self-interested does not restrict you to playing a zero-sum game, where there is only one winner, but could make you a better player in a non-zero-sum game to find a win-win solution.

The second lab experiment is about 'The Ultimatum Bargaining Game' also known as 'Dictator Game', the design is simple, one of the participants is assigned the role of allocator and asked to allocate a fixed amount of money between her and the recipient, where she has total control of the money and can allocate the money as she wishes. If the recipient accepts the offer of the allocator both will receive the amounts decided by the allocator, if the recipient rejects the offer both players walk away empty handed. The assumption behind the game is that if the bargainers are self-interested they would try to maximise their portion of money. If the assumption is true then any rational self-interested person, knowing that the allocator has a total control over money would accept the money that is offered regardless how small it is, which is better than none (Cropanzano, Stein \& Goldman, 2007). Again results were surprising, when the offer was less that 50/50; recipients tend to reject the offer. Why do people act irrationally and against their self-interest? Even though gaining some money is important, they also care whether it is distributed justly and if they perceive it to be unjust, although it is against their selfinterest they prefer to punish the unjust behaviour and in order to punish this they are willing to pay for it.

What do these experiments tell us? First of all, to be self-interested does not always necessitate a zero-sum game where there is only one winner, situations tell us that it is also for our best interest to play a non-zero sum game and arrive at a win-win solution, by considering the other party's interest. Analysing the consequences of alternative actions and choosing the one that serves the interest of all parties as much as possible by arriving at a win-win solution is not incompatible with maximizing profit. As the results of the Ultimatum Game show, people are willing to punish a perceived unjust act even if it also detrimental to themselves. Knowing that tendency also triggers a motive to cooperate and look for a win-win solution. How does this apply to our business decisions? It will help us to see the long term effect of the consequences of alternative actions on others and we could calculate how it would affect the bottom-line. 
In business terms, it could be acceptable to a take certain risk as a consequence of doing business, it would be a calculated risk. But it is not acceptable to take a risk by thinking that you can get away with it without calculating the magnitude of its effect on the firm. If Volkswagen knew the consequences of cheating on the emission test both financially and socially, would it dare to do it? Knowing the consequences, would Volkswagen's former CEO Martin Winterkorn let the company take the same action today? Stakeholders have access to information more than ever and this gives them opportunity to act in their own self-interest and punish if necessary. A utilitarian framework would support business to be honest and consider others' needs in order to achieve their goal.

It has been shown that empirical studies on ethical decision making processes show that there are many components that affect this process. Examples of corporate scandals show that companies that seem to have established mechanisms to enforce ethical behaviour still commit unethical acts. . Having codes of ethics, performance management systems, whistle blowing policies do not prevent corruption. Companies are bound to work within law, thus rather than trying to force them to work according to ethical standards of society, which could also be relative from society to society, legislations needs to enforce basic universally accepted business norms. Only through this is a company which cannot use child labour in its home country cannot use child labour in some other country. Only in this way could a company sincerely apply a utilitarian approach. If a utilitarian framework is applied, executives will see that disciplining everyone including 'high valued' and/or 'high status' employees when they trespass the code of ethics, rewarding salespeople who do not deceive their customers, training employees to raise ethical awareness, and informing them how consequences of their action effects them and the company, will show its effects on the bottom-line in the long run. Business for sure is aware of the importance of long term success.

\section{References}

[1] Bakan, Joel (2004), The Corporation: The Pathological Pursuit of Profit and Power. Constanle: London. Kindle edition.

[2] Brady, F. N., \& Wheeler, G. E.(1996). An empirical study of ethical predispositions. Journal of Business Ethics, 16, 927-940.

[3] Craft, Jana L. (2013) A Review of the Empirical Ethical Decision-Making Literature: 2004-2011. Journal of Business Ethics, 117, pp. 221-259.

[4] Cohen, J.R., Pant, L.W. and Sharp, D. (1993), A validation and extension of a multidimensional ethics scale, Journal of Business Ethics, Vol.12 No.1, pp. 13-26.

[5] Collins, J.W. (1994, September/October). Is Business Ethics an Oxymoron? Business Horizons, 37(5), 1-8.

[6] Cropanzano, R., Stein, J., \& Goldman, B. M. (2007). Individual aesthetics: Self-interest. In E. H. Kessler \& J. R. Bailey (Eds.), Handbook of organizational and managerial wisdom. Los Angeles, CA: Sage. pp. 181-221.

[7] Deshpande, S. P. (2009). A study of ethical decision making by physicians and nurses in hospitals. Journal of Business Ethics, 90, 387-397. Doi:10.1007/s10551-009-0049-5.

[8] Eisenstein, Paul A., (Oct 9 2015). Could Rogue Software Engineers Be Behind VW Emissions Cheating? Retrieved April 19, 2017, from http://www.nbcnews.com/business/autos/could-rogue-software-engineers-bebehind-vw-emissions-cheating-n441451.

[9] Ferraro, F., Pfeffer, J. \& Sutton, R. I. (Jan 2005) Economics Language and Assumptions: How Theories Can Become Self-Fulfilling. Academy of Management Review. Vol. 30 Issue 1, pp.8-24.

[10] Friedman, M. (1970, September 13). The Social Responsibility of Business Is to Increase Its Profit. New York Times Magazine, 32-33.

[11] Fritzche, J.D., Becker, H. (1984), Linking Management Behavior to Ethical Philosophy - An Empirical Investigation. Academy of Management Journal, Vol.27 No. 1, pp. 166-175.

[12] Fryer, Mick (2015). Ethics Theory and Business Practice (London: Sage Publications)

[13] Greene, Joshua (2013). Moral Tribes: Emotion, Reason, and the Gap Between Us and Them. Atlantic Books: London. Kindle edition. 
[14] Harinck, F., C. K. W. De Dreu, et al. (2000). The impact of conflict issues on fixed-pie perceptions, problem solving, and integrative outcomes in negotiation. Organizational Behavior and Human Decision Processes 81(2): 329-358; in Greene (2013).

[15] Kant, Immanuel (2006) Groundwork of the Metaphysics of Morals, trans. and ed. Mary Gregor, Cambridge: Cambridge University Press.

[16] Kish-Gephart, J.J., Harrison, D.A. and Trevino,L.K., (Jan 2010) Bad apples, bad cases, and bad barrels: metaanalytic evidence about sources of unethical decisions at work. Journal of Applied Psychology Vol. 95 Issue 1, pp.1-31.

[17] Lawhead, William F. (2011). The Philosophical Journey: An Interactive Approach. 5th ed. New York: McGrawHill.

[18] Miller, Dale T (Dec 1999) The Norm of Self-Interest. The American Psychologist. Vol. 54 Issue 12, pp.1053 - 8.

[19] O'Fallon, M.and Butterfield, D. (2005) A Review of the Empirical Decision-Making Literature: 1996-2003. Journal of Business Ethics 59, 375-394.

[20] Plato (1974). Desmond Lee (trans) The Republic, London: Penguin Books.

[21] Premeaux, Shane R. (2004) The Current Link Between Management Behavior and Ethical Philosophy. Journal of Business Ethics, Vol. 51, Issue 3, p. 269-278.

[22] Rosen, B. and Jerdee, T.H. (1974) Factors Influencing Disciplinary Judgements. Journal of Applied Psychology, Vol. 59, No. 3, 327-331.

[23] Rousseau, Jean-Jacques (2015). The Social Contract. Wallanchia Publishers: New York. Kindle edition.

[24] Treviño, L. K.. \& Youngblood, S. A. (1990). Bad apples in bad barrels: A causal analysis of ethical decisionmaking behavior. Journal of AppliedPsychology, 75, 378-385.

[25] Zhang, J., Chiu, R., \& Wei, L. (2009). Decision-making process of internal whistleblowing behavior in China: Empirical evidence and implications. Journal of Business Ethics, 88, 25-41.doi:10.1007/s10551-008-9831-z. 